\title{
A novel wavelet packet transform based fault identification procedures in HV transmission line based on current signals
}

\author{
Ahmed R. Adly ${ }^{1}$, Ragab A. El Sehiemy ${ }^{2}$, Mahmoud A. Elsadd ${ }^{3}$, Almoataz Y. Abdelaziz ${ }^{4}$ \\ ${ }^{1}$ ETRR-2, Electrical Engineering Department, Nuclear Research Center, Atomic Energy Authority Egypt \\ ${ }^{2}$ Electrical Engineering Department, Faculty of Engineering, Kafrelsheikh University, Egypt \\ ${ }^{3}$ Electrical Power \& Machines Department, Faculty of Engineering, Menoufia University, Egypt \\ ${ }^{4}$ Electrical Power \& Machines Departemnt, Faculty of Engineering, Ain Shams University, Egypt
}

\begin{tabular}{l} 
Article Info \\
\hline Article history: \\
Received Aug 9, 2018 \\
Revised Oct 11, 2018 \\
Accepted Dec 28, 2018 \\
\hline Keywords: \\
Fault identification \\
Permanent fault \\
Single pole adaptive reclosure \\
Transient fault \\
Transmission lines \\
Wavelet packet transform
\end{tabular}

\section{Corresponding Author:}

Ahmed R. Adly, ETRR-2, Electrical Engineering Departement,

Nuclear Research Center, Atomic Energy Authority 13759, Cairo, Egypt.

Email: ahmed.adly@eaea.org.eg

\begin{abstract}
This paper presents an adaptive fault identification algorithm bases on wavelet packet transform (WPT) for two-terminal power transmission lines. The proposed scheme performs four functions which are the fault detection, fault classification, distinguishing among the temporary and the permanent faults, and detection of the arc extinguish instant. The presented algorithm only uses the measured current at one terminal reducing the required cost. Also, it can mitigate the error resulting from the load variations via updating the presetting value. Consequently, it does not need retesting under changing the transmission system configurations. The proposed scheme is deduced in the spectral domain and depended on the application of the WPT. The db6 wavelet packet is used for decomposing the faulty phase current waveform (level 7) to get the energy coefficients. The presented algorithm is assessed under various fault conditions such as fault distances, inception angles, and faults nature via simulating different secondary arc models via using ATP/EMTP. The obtained results are investigated and evaluated.
\end{abstract}

Copyright $\odot 2019$ Institute of Advanced Engineering and Science. All rights reserved.

\section{INTRODUCTION}

Transmission lines (TLs) are considered as crucial parts of electrical power systems. They help to meet the electrical demands of industrial, commercial, domestic, and rural consumers (among others). Therefore, the transmission line protection malfunction may affect a significant number of consumers. To avoid damage in such important power system components, adequate protection schemes for TLs are necessary function for initiating the protection reaction after the fault inception as soon as possible [1]. Transmission lines operation suffers from different challenges such as detecting the fault, identifying the faulty line that must be cleared under single-line-to-ground fault, identifying the fault nature, and identifying the suitable instant of the closing decision for the isolated pole after the arc extinction under temporary faults. The single pole tripping can enhance the transient stability. Therefore, the fault classification and the fault nature discrimination are important tasks [2], [3], whereas a precise automatic reclosing in the decision to the isolated line under the temporary faults can enhance the network reliability [4]. While, the successful autoreclosure is dependent on the verification of the following tasks: fault detection, classification, fault nature discrimination and able to detect the correct instant of arc extinguish [5].

Regarding the fault detection and classification tasks, a wide area back-up protection scheme is presented based on phasor measurement unit's measurements. A. R. Adly, et al [6] presented scheme based on combination between DWT and karen bell transformation (KBT) for fast fault detection and classification. The average of fault detection time is $1.25 \mathrm{~ms}$, also is applied in single TL and WSCC 9-bus system. 
S. R. Samantaray [7] provided a systematic fuzzy rule- based algorithm for fault classification. This scheme begins with preprocessing the current signal based on S-transform. After the required features are extracted by S-transform, the decision tree (DT) is used for initial classification, and then fuzzy logic (FL) rule-base is derived for final identification. H. Livani and C. Y. Evrenosoğlu [8] introduced fault classification and localization scheme combines the merits of discrete wavelet transform (DWT) and support vector machine (SVM) for transmission lines (TLs). The DWT is employed to obtain the transient information existed in the voltages signals while SVM classifies the fault type. In this regard, massive trainings are required in order to cover all the expected operating circumstances. Therefore, its implementation is complex in the industry real field [9]. A current signal based fault identification scheme is presented for the adaptive cumulative sum method [10]. The proposed method didn't take into account the distributed capacitance of the transmission line which limits its capabilities to be generalized in actual TLs especially long TLs. A scheme presented on the basis of combined WT and regression tree (RT) method [11]. The currents signals are decomposed by WT and then the wavelet coefficients used as an input to regression tree algorithm. Y. Usama, et al [12] provided the WT contemplates the high-frequency transients analysis resulted from the fault occurrence. The amount of high frequency components in the range of $5-10 \mathrm{kHz}$ identifies the fault. S. Dasa et al [13] provided a new scheme for fault detection, classification and location using only voltage measurements obtained from wide area measurement systems (WAMS) and the network bus admittance matrix has been presented.

On the other hand, several schemes have implemented the adaptive single pole autoreclosure (ASPAR) tasks. A review of different adaptive autoreclosure techniques was introduced, and then an adaptive single pole tripping was presented based on WPT [4]. ASPAR techniques can be divided to communication schemes [14] and non-communication schemes [4]. The lack of reliability of the communication schemes is the major defect. A DFT-scheme was presented for fault identifications process [14]. It was dependent on the voltage and current signals recorded at two sides of transmission lines. The scheme was able to correctly discriminate type of the fault. A. R. Adly, et al [15] presented a WPT scheme for adaptive single pole autoreclosure to distinguish the faults' nature and to determine the arc extinguish instant. The presented scheme was based on the magnitude and the angle of the local faulty phase voltage [16]. One of the effective advantages of this scheme is the quick identifying of the fault type.

The DC offset value of zero-sequence voltage was used in order to identify the faults' natures. The scheme employed the third order harmonic of the voltage signals to distinguish the instant of arc extinction. This scheme cannot differentiate correctly among the permanent and the transient faults until secondary arc extinction appears [17]. The fast Fourier transform was employed as a signal processing method, and then ANN is developed for final reclosing decision [18]. Gabor transform (GT) was developed to obtain data features from each simulated fault [19]. The extracted GT coefficients were utilized as the inputs to ANN. Generally for schemes [16-19] that were depended on the faulty phase voltage, the lack of a voltage transducer restricts the application of these schemes.

To overcome the previous voltage problem, the proposed scheme in this paper only analyzes the current signals to perform four identification process functions which are fault detection; fault classification; discrimination between transient and permanent faults; and detection of the accurate instant of arc extinguish. In this paper, a new WPT-based scheme is investigated for achieving the identification process functions. The WPT energy nodes are calculated after analyzing the current signals. The proposed scheme covers both low and high frequency components to enhance performance of the scheme. It, also, continuously monitors the load current and, then, adaptively changes the threshold value. The scheme uses the harmonics spectrum of the mode current to discriminate between the faults' nature and detect the instant of the arc extinguish. To validate the proposed scheme performance, it was extensively evaluated in simulations carried out in ATPEMTP program under several fault situations. The evidence of the capability of the presented algorithm is well proven compared with other existed methods.

\section{DESCRIPTION OF PROPOSED SCHEME}

A new fault identification scheme is presented. The presented scheme is able to perform the following functions that are fault detection; fault classification; discriminating the faults' natures; and identifying the arc extinguish instant. The presented methodology for classifying and detecting the fault comprises the components of low and high frequencies that improve the proposed scheme response. In addition, the methodology continuously investigates the load current and, then, varies the threshold value. Hence, the threshold value is adaptive. The non-linear characteristic of the arcing faults results mode current distortions. The $2 \mathrm{nd}$, 3rd, 4th and 5th harmonic orders have higher values than other harmonics via analyzing the harmonics spectrum of the mode current. Also, the variation among its level before and after the extinction of the arc is significant. Thus, the presented scheme employs the mode current harmonics' 
amplitude as the most suitable parameter that gives a reliable indication for distinguishing among transient and permanent faults. The flow chart of the presented methodology is illustrated in Figure 1.

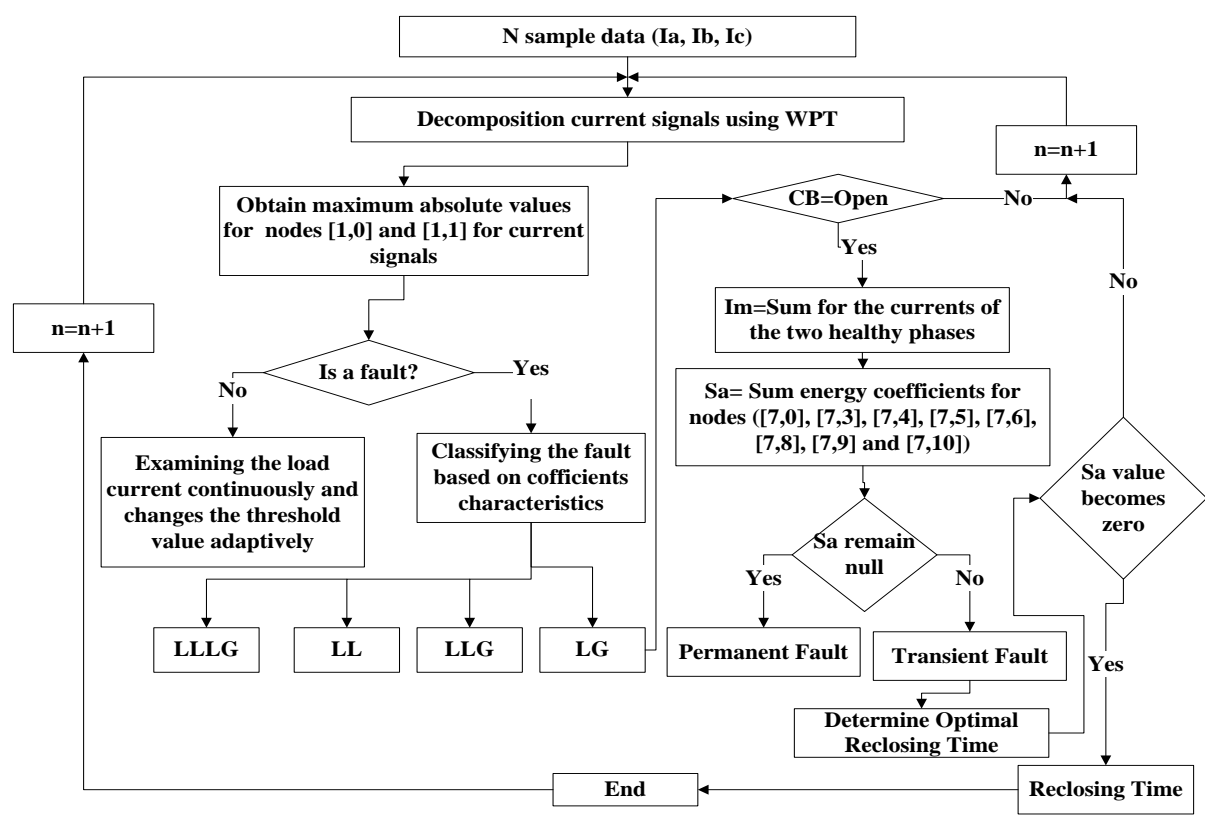

Figure 1. Protection scheme framework

The fault identification scenario is as follows:

a. Sampling the current signal at $6.4 \mathrm{kHz}$.

b. Decomposing three phase current signals $\left(\mathrm{I}_{\mathrm{a}}, \mathrm{I}_{\mathrm{b}}\right.$, and $\left.\mathrm{I}_{\mathrm{c}}\right)$ and the ground current $\mathrm{I}_{\mathrm{g}}$.

c. Decomposing the sampled current signal utilizing db6 wavelet into level 7 to calculate the energy coefficients nodes at various low and high frequency ranges as shown in Table 1.

a. Calculating the maximum absolute values for approximation coefficient of current signals $\left(S_{a} S_{b} S_{c}, S_{g}\right)$ in node $[1,0]$ and that value for detailed coefficients of current signals $\left(D_{a}, D_{b}, D_{c}\right)$ in node $[1,1]$ of the decomposed currents.

b. Identifying the types of the fault with identifying the proper trip characteristics, the schemes can identify the fault circumstances based on the rules that are reported in Table 2.

c. After the fault is classified as single phase to ground fault, the two healthy phases' currents are recording (mode current) to determine the fault nature (transient or permanent). The mode current will be calculated as the following:

$\boldsymbol{I}_{\text {mode }}=\boldsymbol{I}_{b}+\boldsymbol{I}_{c}$, under considering that the faulty phase is phase a.

$\boldsymbol{I}_{\text {mode }}=\boldsymbol{I}_{a}+\boldsymbol{I}_{c}$, under considering that the faulty phase is phase b.

$\boldsymbol{I}_{\text {mode }}=\boldsymbol{I}_{a}+\boldsymbol{I}_{b}$, under considering that the faulty phase is phase c.

Computing the energy coefficient index $S_{t}$ of mode current for distinguishing among permanent and transient faults and determining the time of secondary arc extinction. Therefore, the energy coefficient indices at nodes $[7,3],[7,4],[7,5],[7,6],[7,7],[7,8],[7,9]$ and $[7,10]$ are computed as:

$$
S_{t}=\sum_{i=1}^{N} \sum_{K=[7,3]}^{[7,10]} d_{K}^{2}(i)
$$

where $\mathrm{dk}$ and $\mathrm{N}$ are the coefficients and the number of coefficients at node $\mathrm{k}$, respectively,

d. The index St is used to distinguish permanent versus transient faults and to find the extinction instant of the secondary arc. After interrupting the breakers, if the index does not vary and still null, then, the fault type is permanent. On the other hand, the fault is identified as temporary. Under these temporary faults, 
the value of the presented index changes to be zero after quenching the secondary arc. Therefore, the extinction time of the secondary arc can further obtained via evaluating this index. It should be noted that the calculation of the index St starts after isolating the faulty phase from two sides. Furthermore, this calculation is lagged by a cycle to overcome the transient resulted during the circuit breakers' interrupting period.

e. Finally for healthy condition (no fault) accomplished with considerable difference among the RMS current and the stored load current value, that reflects the variation in generating operating conditions. In such case, the threshold ( $\mathrm{S}$-th) is still constant unless the new load value is settled at this condition for 3 consecutive cycles period at power frequency.

Table 1. Proposed Level 7 Energy Nodes for Different Frequency Ranges

\begin{tabular}{|c|c|c|c|c|c|}
\hline \multirow{2}{*}{ Node } & \multicolumn{2}{|c|}{ Frequency range in $\mathrm{Hz}$} & \multirow{2}{*}{ Node } & \multicolumn{2}{|c|}{ Frequency range in $\mathrm{Hz}$} \\
\hline & From & to & & From & to \\
\hline Node $[1,0]$ & 0 & 1600 & Node $[7,6]$ & 150 & 175 \\
\hline Node $[1,1]$ & 1600 & 3200 & Node $[7,7]$ & 175 & 200 \\
\hline Node $[7,3]$ & 75 & 100 & Node $[7,8]$ & 200 & 225 \\
\hline Node $[7,4]$ & 100 & 125 & Node $[7,9]$ & 225 & 250 \\
\hline Node $[7,5]$ & 125 & 150 & Node $[7,10]$ & 250 & 275 \\
\hline
\end{tabular}

Table 2. Conditions Rules for Fault Classification

\begin{tabular}{|c|c|c|c|c|}
\hline Fault type & $\begin{array}{l}S_{a} \\
D_{a}\end{array}$ & $\begin{array}{l}S_{b} \\
D_{b}\end{array}$ & $\begin{array}{l}S_{c} \\
D_{c}\end{array}$ & $S_{a}$ \\
\hline AG & $\begin{array}{c}S_{a}>S_{t h} \\
D_{a}>D_{t h}\end{array}$ & $\begin{aligned} S_{b} & <S_{t h} \\
D_{b} & <D_{t h}\end{aligned}$ & $\begin{aligned} S_{c} & <S_{t h} \\
D_{c} & <D_{t h}\end{aligned}$ & $S_{g}>S_{g t h}$ \\
\hline BG & $\begin{aligned} S_{a} & <S_{t h} \\
D_{a} & <D_{t h}\end{aligned}$ & $\begin{array}{c}S_{b}>S_{t h} \\
D_{b}>D_{t h}\end{array}$ & $\begin{aligned} S_{c} & <S_{t h} \\
D_{c} & <D_{t h}\end{aligned}$ & $S_{g}>S_{g t h}$ \\
\hline CG & $\begin{array}{l}S_{a}<S_{t h} \\
D_{a}<D_{t h}\end{array}$ & $\begin{array}{l}S_{b}<S_{t h} \\
D_{b}<D_{t h}\end{array}$ & $\begin{array}{l}S_{c}>S_{t h} \\
D_{c}>D_{t h}\end{array}$ & $S_{g}>S_{g t h}$ \\
\hline $\mathrm{ABG}$ & $\begin{aligned} S_{a} & >S_{t h} \\
D_{a} & >D_{t h}\end{aligned}$ & $\begin{array}{c}S_{b}>S_{t h} \\
D_{b}>D_{t h}\end{array}$ & $\begin{array}{l}S_{c}<S_{t h} \\
D_{c}<D_{t h}\end{array}$ & $S_{g}>S_{g t h}$ \\
\hline BCG & $\begin{aligned} S_{a} & <S_{t h} \\
D_{a} & <D_{t h}\end{aligned}$ & $\begin{array}{l}S_{b}>S_{t h} \\
D_{b}>D_{t h}\end{array}$ & $\begin{array}{l}S_{c}>S_{t h} \\
D_{c}>D_{t h}\end{array}$ & $S_{g}>S_{g t h}$ \\
\hline ACG & $\begin{aligned} S_{a} & >S_{t h} \\
D_{a} & >D_{t h}\end{aligned}$ & $\begin{array}{c}S_{b}<S_{t h} \\
D_{b}<D_{t h}\end{array}$ & $\begin{array}{l}S_{c}>S_{t h} \\
D_{c}>D_{t h}\end{array}$ & $S_{g}>S_{g t h}$ \\
\hline $\mathrm{AB}$ & $\begin{array}{l}S_{a}>S_{t h} \\
D_{a}>D_{t h}\end{array}$ & $\begin{array}{l}S_{b}>S_{t h} \\
D_{b}>D_{t h}\end{array}$ & $\begin{array}{l}S_{c}<S_{t h} \\
D_{c}<D_{t h}\end{array}$ & $S_{g}<S_{g t h}$ \\
\hline $\mathrm{BC}$ & $\begin{array}{c}S_{a}<S_{t h} \\
D_{a}<D_{t h}\end{array}$ & $\begin{array}{l}S_{b}>S_{t h} \\
D_{b}>D_{t h}\end{array}$ & $\begin{array}{c}S_{c}>S_{t h} \\
D_{c}>D_{t h}\end{array}$ & $S_{g}<S_{g t h}$ \\
\hline $\mathrm{AC}$ & $\begin{array}{l}S_{a}>S_{t h} \\
D_{a}>D_{t h}\end{array}$ & $\begin{array}{l}S_{b}<S_{t h} \\
D_{b}<D_{t h}\end{array}$ & $\begin{array}{l}S_{c}>S_{t h} \\
D_{c}>D_{t h}\end{array}$ & $S_{g}<S_{g t h}$ \\
\hline $\mathrm{ABCG}$ & $\begin{array}{l}S_{a}>S_{t h} \\
D_{a}>D_{t h}\end{array}$ & $\begin{array}{l}S_{b}>S_{t h} \\
D_{b}>D_{t h}\end{array}$ & $\begin{array}{l}S_{c}>S_{t h} \\
D_{c}>D_{t h}\end{array}$ & $S_{g}<S_{g t h}$ \\
\hline
\end{tabular}

\section{SIMULATION AND DISCUSSION}

\subsection{Test system}

The simulation of the tested power system is carried out using ATP/EMTP at a sampling rate of 6.4 $\mathrm{kHz}$. The system is depicted in Figure 2. The parameters of the simulated 500kV transmission line having $350 \mathrm{~km}$ long are listed in Table 3 [20].

A

B

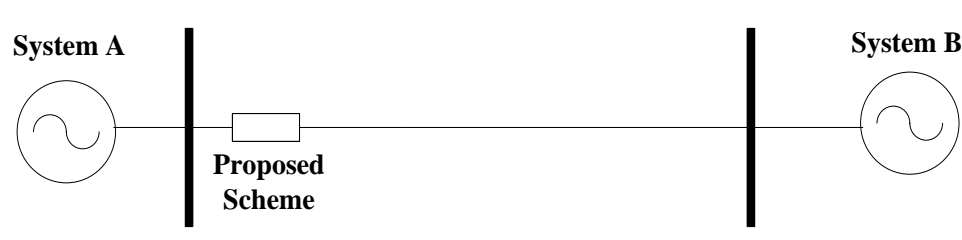

Figure 2. Single line diagram of tested $500 \mathrm{kV}$ system 
Table 3. The Simulated Transmission System Parameters

\begin{tabular}{ccc}
\hline \multicolumn{2}{c}{ Line voltage } & $500 \mathrm{kV}$ \\
\hline Equivalent impedance behind terminal A $\left(\varphi=0^{\circ}\right)$ & Positive sequence $(\Omega)$ & $18+43.1749 \mathrm{i}$ \\
Equivalent impedance behind terminal B & Zero sequence $(\Omega)$ & $15+30.2221 \mathrm{i}$ \\
$\left(\varphi=-15^{\circ}\right)$ & Positive $(\Omega)$ & $26+44.9185 \mathrm{i}$ \\
& $\mathrm{Zero}(\Omega)$ & $20+37.4698 \mathrm{i}$ \\
Transmission line AB & $\mathrm{Z}_{1}(\Omega / \mathrm{km})$ & $0.00758+0.26365 \mathrm{i}$ \\
& $\mathrm{Z}_{0}(\Omega / \mathrm{km})$ & $0.15421+0.8306 \mathrm{i}$ \\
& $\mathrm{C}_{1}(\mathrm{nF} / \mathrm{km})$ & 13.97 \\
& $\mathrm{C}_{0}(\mathrm{nF} / \mathrm{km})$ & 9.296 \\
\hline
\end{tabular}

From the modeling view point, transient fault can be modeled as high current primary arc during the fault period and low current secondary arc. The ATP/EMTP was employed for modeling the transient fault. Arc is represented by a MODELS controlled switch and a controlled resistance in ATP as illustrated in Figure 3.

For testing HV transmission networks, the suitable arc model utilizing three sets of typical data that lead to three various arc models (Arc1, Arc2, Arc3) is considered. Typical values for the arc parameters were customized from [21]. Also, three parameters were changed around their typical values to produce three various arcs as in Table 4. Validation of the arc modeling technique is done via comparing the modeled arc with some other simulation and real arc waveforms [22].

Table 4. Various Arc Models (Arc1, Arc2 and Arc3) Parameters

\begin{tabular}{cccc}
\hline Arc model & $\mathrm{U}_{0}(\mathrm{v} / \mathrm{cm})$ & $l_{o}(\mathrm{~m})$ & $\tau_{0}(\mathrm{~ms})$ \\
\hline 1 & 11 & 3.5 & 0.692 \\
2 & 12 & 3.5 & 0.824 \\
3 & 8 & 3.15 & 0.553 \\
\hline
\end{tabular}

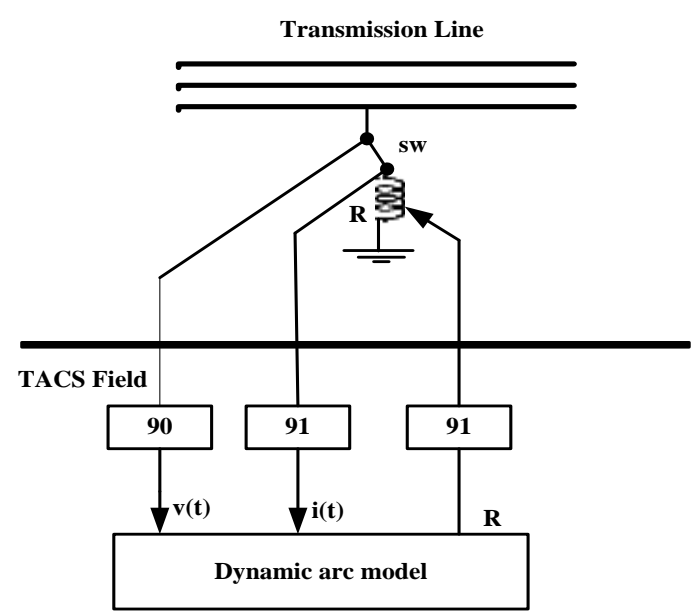

Figure 3. ATP/EMTP network of arcing fault representation using TACS modeling

\subsection{Studied cases}

Numerous simulation test cases are employed to validate the proposed scheme under different fault conditions. The fault circumstances are various fault inceptions, and fault distances. The studied cases to verify the proposed technique can be classified to the following cases:

Case 1: Influence of fault types, fault distances, angles of the fault inception and the fault impedance associated with the internal faults.

Case 2: Load level variation and then adapting the presetting value.

Case 3: Distinguishing the fault type whether it is permanent or temporary fault.

Case 4: Determination of the secondary arc quenching instant.

Case 5: Transmission line under different arc models (Arc1, Arc2, Arc3).

Case 6: Effect of sampling frequency on the scheme. 


\subsection{Response of fault identification scheme}

\subsubsection{Simulation results of case 1}

Several test cases, corresponding to the analyzed case 1 , have been investigated in this section to assess the presented scheme response to detect and classify the fault occurrence and the fault type, respectively. The measured current at one terminal is analyzed via utilizing WPT at level 7 to obtain the maximum absolute value for approximation coefficient of current signals in node [1, 0] and maximum absolute value for detailed coefficients of current signals in node $[1,1]$. The magnitude of the healthy phase is much lower than faulted phases. The extremely significant difference among the healthy and faulty phases is retained under various fault types. Also, different fault distances under all shunt fault types are investigated. Table 5 and 6 confirm that the proposed scheme can identify the fault types.

Table 5. Results of fault classification for different fault types (at $175 \mathrm{~km}$ away from the bus with fault resistances: $10 \Omega$ )

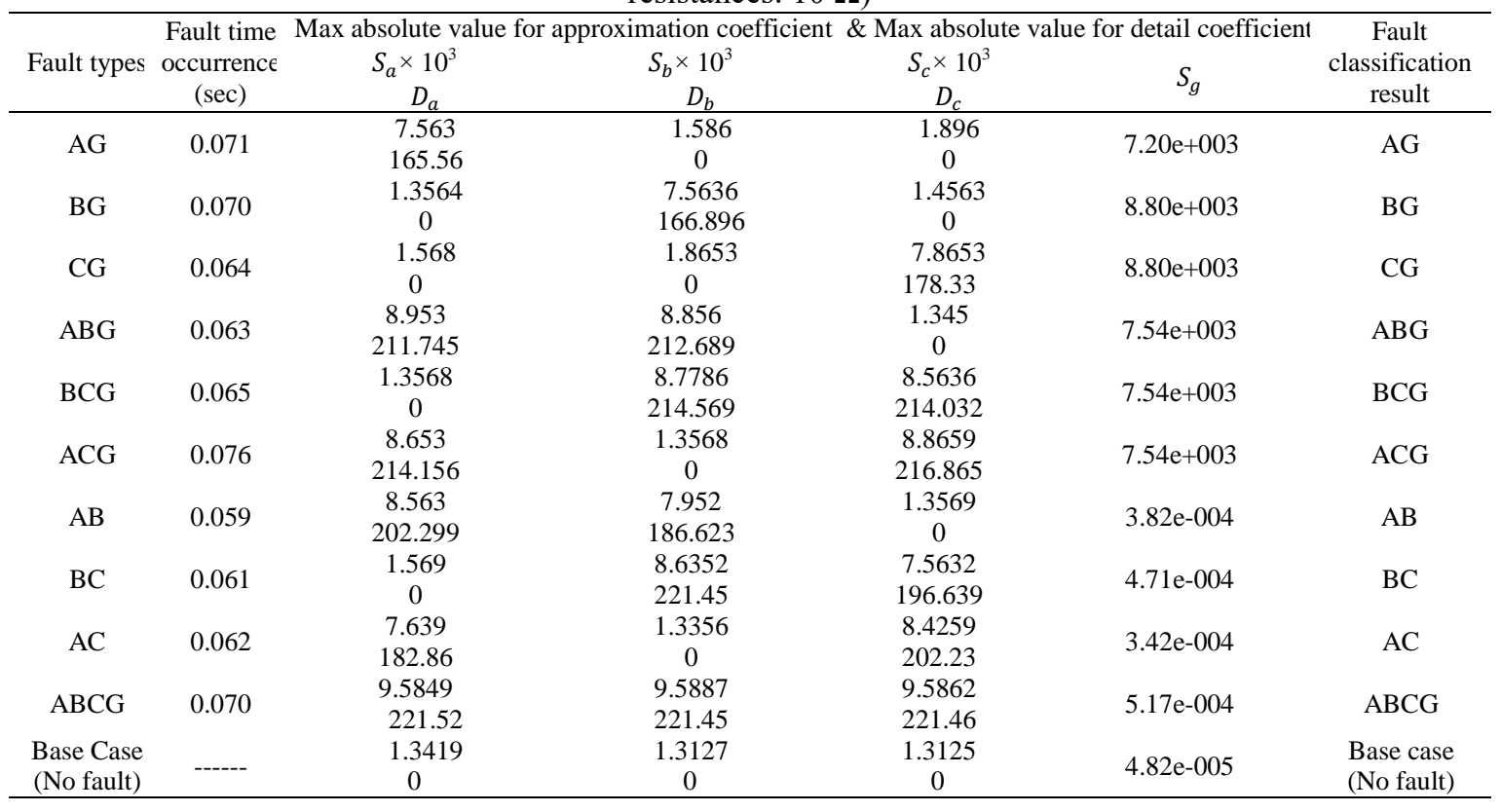

Table 6. Results of fault classification for various fault conditions at the sending bus with fault resistances: $100 \Omega$

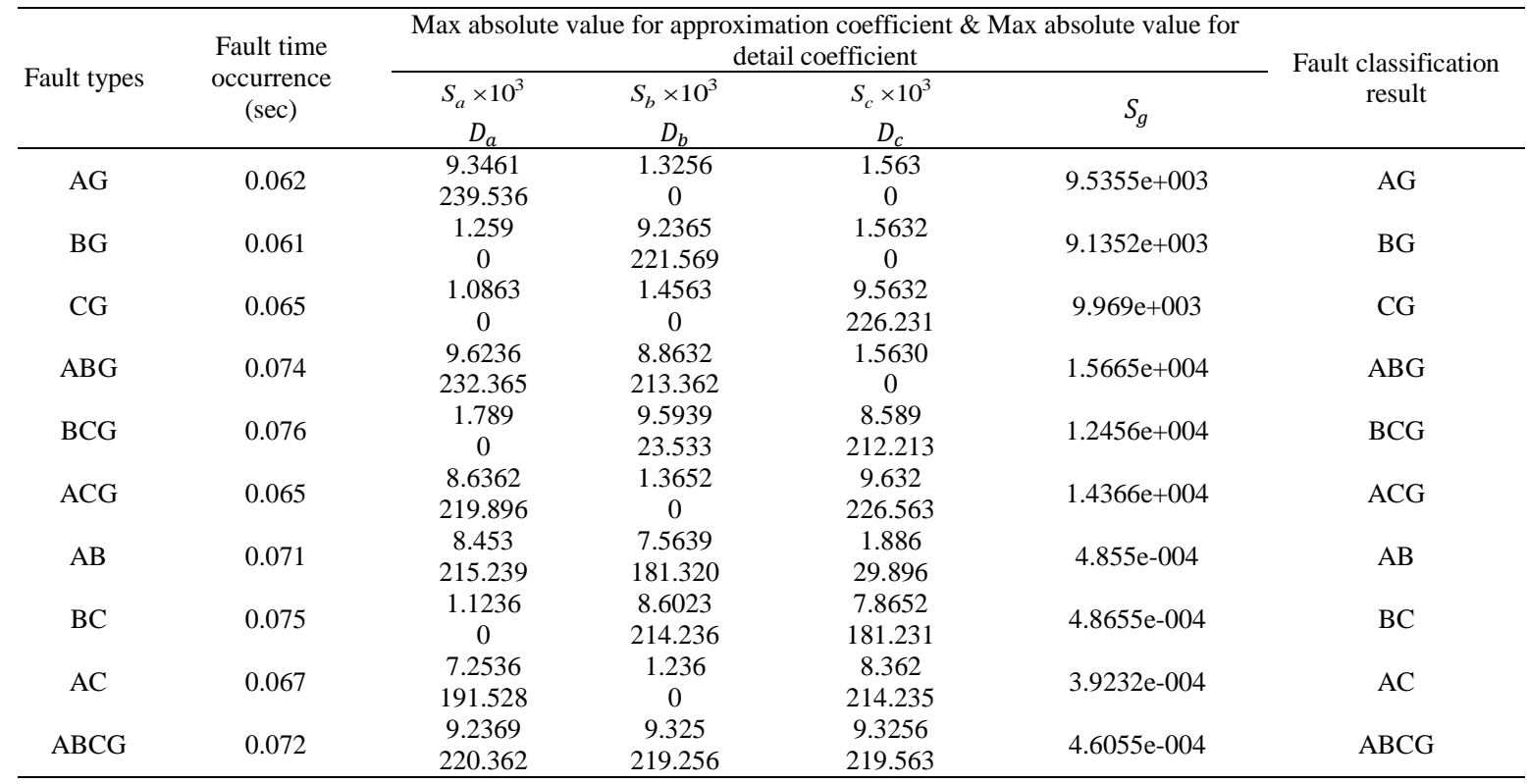




\subsubsection{Simulation results of case 2}

Figure 4 illustrates the scheme maximum absolute value of approximation coefficient of current signals in node [1,0] and maximum absolute value of detailed coefficient of current signals in node [1, 1] under both different load levels and three phase short circuits. The results confirm that no significant change in the maximum absolute value of current detailed coefficient $\left(D_{a}, D_{b}, D_{c}\right)$ is occurred under normal load changing.

Also, no a mal-operation for the presented method is happened due to probable changes of the normal load because the presetting value is updated based on the current load level. Consequently, the presented method can correctly compile a significant change for the load level whether the change is increasing or decreasing where the presented feature does not exceed the presetting value for more than three cycles.

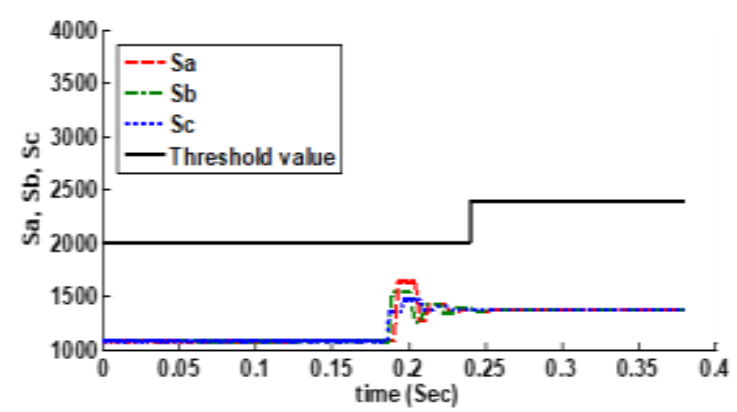

(a) $S_{a}, S_{b}, S_{c}$ for load changing

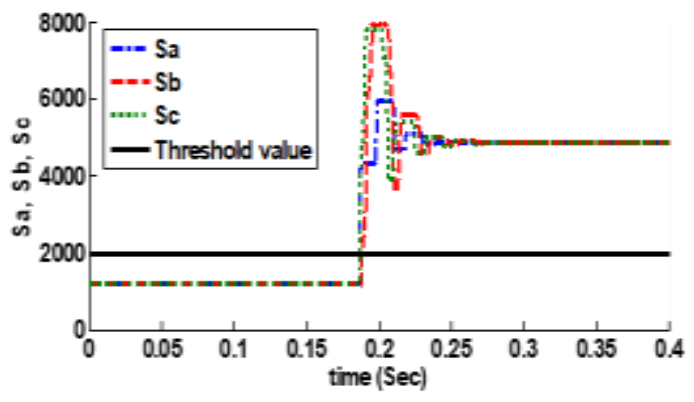

(c) $S_{a}, S_{b}, S_{c}$ for three phase short circuit

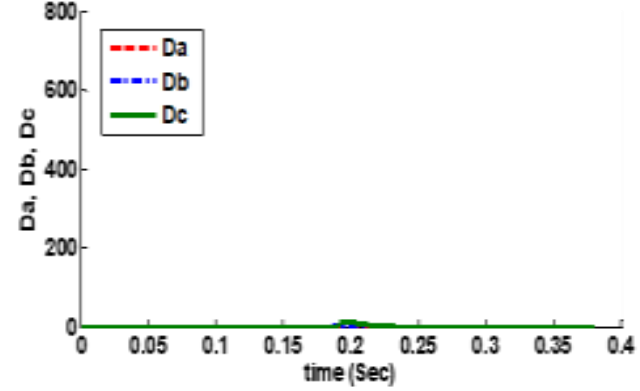

(b) $\mathrm{D}_{\mathrm{a}}, \mathrm{D}_{\mathrm{b}}, \mathrm{D}_{\mathrm{c}}$ for load changing

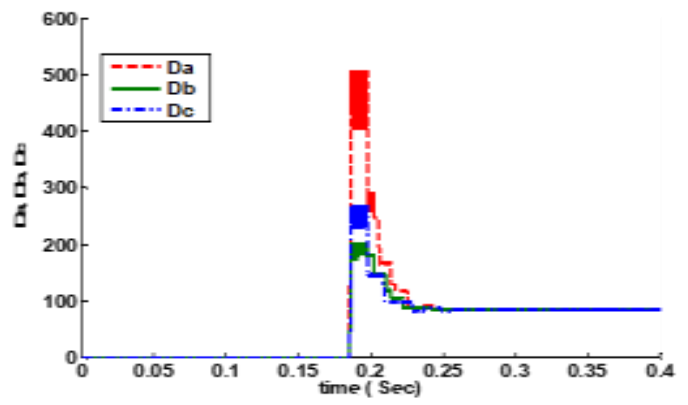

(d) $D_{a}, D_{b}, D_{c}$ for three phase short circuit

Figure 4. Load changing and three phase short circuit

\subsubsection{Simulation results of case 3}

In this case, the presented method is investigated under a line-to-ground (AG) fault that occurs at $0.08 \mathrm{~s}$ instant with various distances. The breakers are opened at $0.18 \mathrm{sec}$. Figures 4 illustrates the obtained signals under this case by monitoring the behavior of the proposed index $\left(\mathrm{S}_{\mathrm{t}}\right)$ for transient and permanent faults using these various arc models. The results confirm that the suggested index value under of transient fault has a non-zero value, whereas the index becomes zero after quenching the secondary arc. On the other hand, the index remains equals zero without any change under permanent faults as illustrated in Figure 5.

\subsubsection{Simulation results of case 4}

The presented method is also tested under different fault distances and load angles as listed in Table 7 , where $\mathrm{T}_{\text {que }}$ and $\mathrm{T}_{\mathrm{rec}}$ are the instant of both the secondary arc quenching and the reclosing command instant, respectively. Also, under occurring AG fault at the instant $0.1 \mathrm{~s}$ and at $0.2 \mathrm{~s}$, the faulted phase is isolated by interrupting the currents at both ends via breakers. Figure 5 and Table 7 confirm the correct performances of the presented method under various fault distances, fault inception angles, and load angles. 


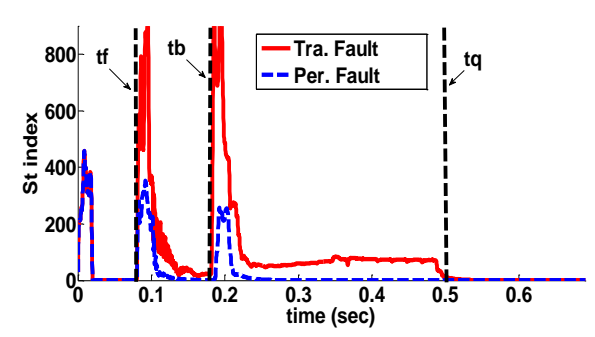

(a) At sending end (zero $\mathrm{km})$

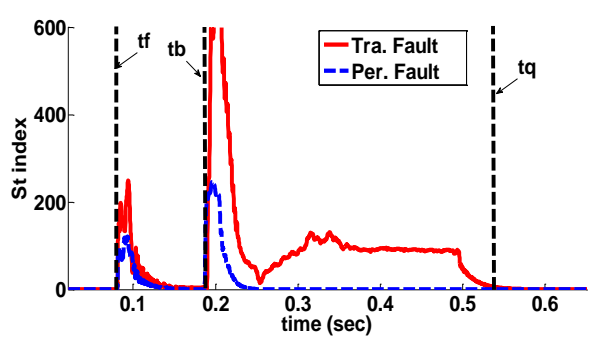

(b) At $210 \mathrm{~km}$

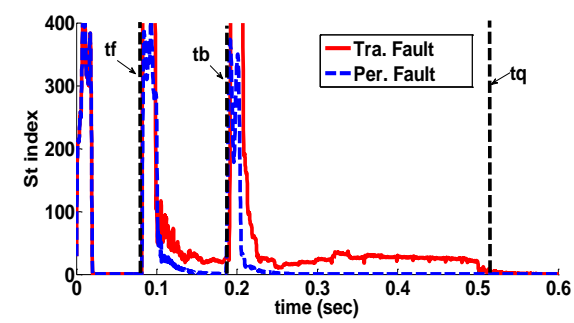

(c) At $320 \mathrm{~km}$

Figure 5. Behavior of index " $\mathrm{S}_{\mathrm{t}}$ " under transient and permanent faults for Case 3 at different fault locations.

Table 7. Total Execution Time of Studied Cases

\begin{tabular}{ccccc}
\hline Load angle $\left(\delta^{\mathrm{o}}\right)$ & Fault location $(\mathrm{km})$ & $\mathrm{T}_{\text {que }}(\mathrm{s})$ & $\mathrm{T}_{\text {rec }}(\mathrm{s})$ & $\mathrm{T}_{\text {exe }}(\mathrm{ms})$ \\
\hline-30 & 0 & 0.631 & 0.648 & 17.35 \\
-15 & 90 & 0.592 & 0.608 & 16.38 \\
0 & 170 & 0.652 & 0.671 & 19.62 \\
15 & 340 & 0.686 & 0.704 & 18.29 \\
-20 & 20 & 0.565 & 0.584 & 19.51 \\
-10 & 120 & 0.582 & 0.600 & 18.61 \\
0 & 250 & 0.534 & 0.552 & 18.02 \\
20 & 310 & 0.568 & 0.585 & 17.95 \\
-25 & 30 & 0.627 & 0.645 & 18.35 \\
-5 & 160 & 0.636 & 0.655 & 19.01 \\
0 & 190 & 0.646 & 0.664 & 18.92 \\
25 & 290 & 0.695 & 0.714 & 19.27 \\
-30 & 60 & 0.508 & 0.527 & 19.06 \\
-10 & 135 & 0.562 & 0.580 & 18.86 \\
0 & 220 & 0.506 & 0.523 & 17.92 \\
10 & 300 & 0.547 & 0.566 & 19.06 \\
\hline Note: $\mathrm{T}_{\text {exe }}=\mathrm{T}_{\text {rec }}-\mathrm{T}_{\text {que }}$ & & & & \\
\hline
\end{tabular}

\subsubsection{Simulation results of case 5}

Case 5 has been carried out to investigate the presented method ability to distinguish among both permanent and temporary faults using three different arc models (Arc1, Arc2, and Arc3). Figures 6 depicts the obtained signals under case 5 by monitoring the behavior of the proposed index $\left(\mathrm{S}_{\mathrm{t}}\right)$ for transient and permanent faults using these various arc models. The results confirm that the suggested index value under of transient fault has a non-zero value, whereas the index becomes zero after quenching the secondary arc. On the other hand, the index remains equals zero without any change under permanent faults.

\subsubsection{Simulation results of case 6}

Case 6 presents the effect of sampling frequency on the behavior of the presented scheme. The sampling frequency is chosen as $6.4 \mathrm{kHz}$ in this paper. The used sampling rate is set as $f_{s}=6.4 \mathrm{kHz}$ (i.e., 128 samples /cycle at $50 \mathrm{~Hz}$ ) for a system operating at a frequency of $50 \mathrm{~Hz}$ is used; thus, the maximum resolution level can be the $7^{\text {th }}$ level, i.e. $2^{\mathrm{N}}=128=2^{7}$. In this paper, the proposed method was tested under similar condition with $\mathrm{f}_{\mathrm{s}}=3.2 \mathrm{kHz}$ (i.e., 64 samples /cycle). A line-to-ground transient (AG) fault type is created as in case 1. Figure 7 shows the behavior of the presented method for two sampling frequencies, 3.2 and $6.4 \mathrm{kHz}$, respectively. Therefore, the sampling rate should be equal to at least $1.6 \mathrm{kHz}$; thus, the maximum resolution level can be the $5^{\text {th }}$ level to determine the proposed indices. 


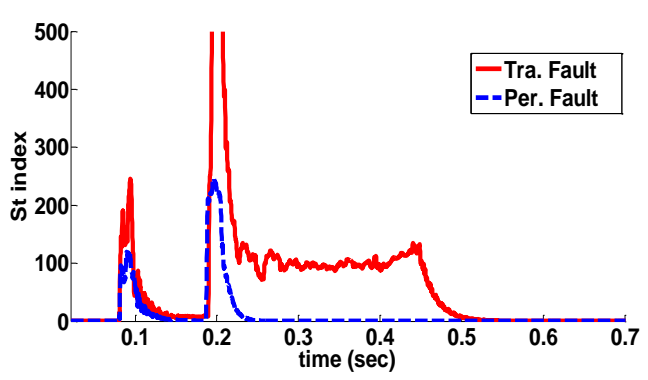

(a) For Arc1

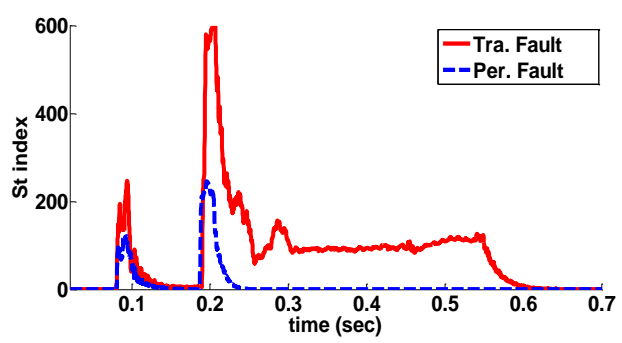

(b) For Arc2

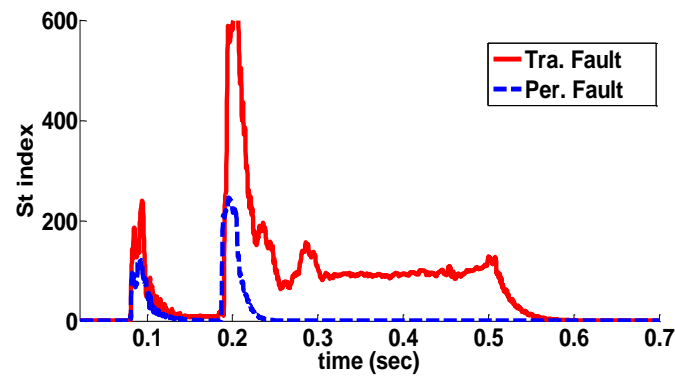

(c) For Arc3

Figure 6. Behavior of index " $\mathrm{S}_{\mathrm{t}}$ " under transient and permanent faults for Case 5 at $170 \mathrm{~km}$ from relay.

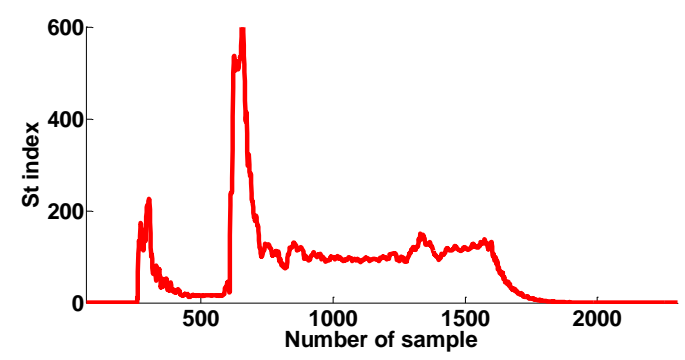

(a) $f_{s}=3.2 \mathrm{kHz}(64$ samples /cycle)

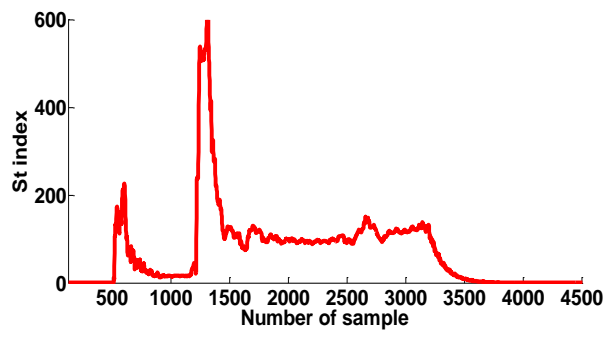

(b) $f_{s}=6.4 \mathrm{kHz}(128$ samples $/$ cycle $)$

Figure 7. Behavior of the proposed technique under different sampling frequency

\section{COMPARISON WITH EXISTING SCHEMES}

Table 8 introduces a comparison among the presented technique and other recently published methods in the literature. The merits of the presented technique compared with the previous methods can be summarized as follows:

a. The logic of the presented technique is deterministic, also avoids the need for collecting historical data which may not be readily available.

b. Moreover, the proposed scheme is free from synchronization problems due to the single end recording of fault current signals.

c. For fault- type classification and fault detection functions, the same feature extraction stage is applied in the proposed scheme thereby improving the its operation speed and making the proposed scheme easier to implement compared with the competitive schemes in the literature.

d. The presetting value is adaptive and relies on the load level to eliminate the problems associated with the fault detection stage under load variations cases.

e. The presented fault classification function is carried out on the basis of high frequency component and low frequency component is precise.

f. The proposed algorithm discriminates correctly between transient and permanent faults.

g. The proposed scheme requires low memory capacity as it extracts only three fault features from three fault current signals. 
Table 8 . The presented scheme versus the corresponding existed scheme

\begin{tabular}{|c|c|c|c|c|c|c|c|}
\hline Basic essence & Process type & Input Data & $\begin{array}{l}\text { Comm./ } \\
\text { Non } \\
\text { Comm. }\end{array}$ & $\begin{array}{l}\text { (D. \& C.) } \\
\text { faults }\end{array}$ & $\begin{array}{l}\text { (D. F.) } \\
\text { natures }\end{array}$ & $\begin{array}{c}\text { Sampling } \\
\text { Frequency }(\mathrm{kHz})\end{array}$ & $\begin{array}{l}\text { Setting } \\
\text { Threshold }\end{array}$ \\
\hline $\begin{array}{c}\text { Proposed WPT } \\
\text { Technique }\end{array}$ & $\begin{array}{l}\text { Directly on current } \\
\text { and harmonic signal }\end{array}$ & $\begin{array}{c}\text { I at single } \\
\text { end }\end{array}$ & Non & $\sqrt{ }$ & $\sqrt{ }$ & 6.4 & Adaptive \\
\hline WPT [4] & On voltage harmonic & $\begin{array}{c}\text { I at single } \\
\text { end }\end{array}$ & Non & $x$ & $\sqrt{ }$ & 6.4 & Adaptive \\
\hline DWT [5] & $\begin{array}{l}\text { Directly on current } \\
\text { signal }\end{array}$ & $\begin{array}{l}\text { I at single } \\
\text { end }\end{array}$ & Non & $\sqrt{ }$ & $x$ & 6.4 & Adaptive \\
\hline $\begin{array}{l}\text { S-transform, DT- } \\
\text { Fuzzy [7] }\end{array}$ & $\begin{array}{c}\text { Directly on current } \\
\text { signal }\end{array}$ & $\begin{array}{l}\text { I at single } \\
\text { end }\end{array}$ & Non & $\sqrt{ }$ & $x$ & 1 & No Need \\
\hline WT \& SVM [8] & $\begin{array}{l}\text { Directly on voltage } \\
\text { signal }\end{array}$ & $\begin{array}{c}\text { I at single } \\
\text { end }\end{array}$ & Comm. & $\sqrt{ }$ & $x$ & 200 & No Need \\
\hline ACUSUM [10] & $\begin{array}{l}\text { Directly on current } \\
\text { signal }\end{array}$ & $\begin{array}{l}\text { I at single } \\
\text { end }\end{array}$ & Non & $\sqrt{ }$ & $x$ & 1 & Fixed \\
\hline WT \& RT [9] & On current harmonic & $\begin{array}{c}\text { I at single } \\
\text { end }\end{array}$ & Non & $\sqrt{ }$ & $x$ & 12.77 & Fixed \\
\hline WT [12] & $\begin{array}{l}\text { On high frequency } \\
\text { component }\end{array}$ & $\begin{array}{c}\text { I at single } \\
\text { end }\end{array}$ & Non & $\sqrt{ }$ & $x$ & 20 & Fixed \\
\hline DFT [14] & On calculated indices & $\begin{array}{c}\text { I \& V at } \\
\text { double end }\end{array}$ & Comm. & $x$ & $\sqrt{ }$ & 3.84 & Fixed \\
\hline WPT [16] & $\begin{array}{c}\text { Directly on voltage } \\
\text { signal }\end{array}$ & $\begin{array}{l}\mathrm{V} \text { at single } \\
\text { end }\end{array}$ & Non & $x$ & $\sqrt{ }$ & 3.84 & Fixed \\
\hline DFT [17] & On voltage harmonic & $\begin{array}{l}\mathrm{V} \text { at single } \\
\text { end }\end{array}$ & Non & $x$ & $\sqrt{ }$ & NR & Adaptive \\
\hline $\begin{array}{c}\text { FFT \& ANN } \\
{[18]}\end{array}$ & On voltage harmonic & $\begin{array}{l}\mathrm{V} \text { at single } \\
\text { end }\end{array}$ & Non & $x$ & $\sqrt{ }$ & NR & No Need \\
\hline GT \& ANN [19] & $\begin{array}{c}\text { Directly on current } \\
\text { signal }\end{array}$ & $\begin{array}{l}\text { I at single } \\
\text { end }\end{array}$ & Non & $x$ & $\sqrt{ }$ & 6.4 & No Need \\
\hline
\end{tabular}

(D. \& C.): Detection and classification; (D. F.): Discriminate fault; Comm.: Communication; and I and V: the phase current and voltage signals, respectively.

\section{CONCLUSION}

The adaptive WPT based protection method is presented for HV transmission networks. The WPT is employed as harmonic extraction tools. The proposed scheme identifies the fault detection, classification, the fault nature, and estimate the fault persistence time of a transient fault via analyzing the harmonic of the phases current using WPT. The novelty of the presented scheme over other existed methods is that the presented scheme is based on an adaptive threshold level and then no special adjustment is required to different transmission systems. Also, the presented algorithm only uses the measured current at one terminal reducing the required cost. For all functions of the proposed scheme, the detection stage is applied improving the overall speed where it is easier to implement. The presented scheme is accurate and reliable for different types of transmission lines faults at various locations and with variations in incidence angles.

\section{REFERENCES}

[1] Y. Zhong, X. Kang, Z. Jiao, Z. Wang and J. Suonan, "A Novel Distance Protection Algorithm for the PhaseGround Fault," in IEEE Transactions on Power Delivery, vol. 29, no. 4, pp. 1718-1725, Aug. 2014.

[2] B. Patel, P. Bera, and B. Saha, "Wavelet Packet Entropy and RBFNN Based Fault Detection, Classification and Localization on HVAC Transmission Line," Electric Power Components and Systems, vol. 46, no.1, pp. 15-26, 2018.

[3] P. Sharma, D. Saini, A. Saxena, "Fault Detection and Classification in Transmission Line using Wavelet Transform and ANN," Bulletin of Electrical Engineering and Informatics, vol. 5, no. 4, pp. 456-465, 2016.

[4] A. R. Adly, R. A. El Sehiemy, A. Y. Abdelaziz, S. A. Kotb, "An Accurate Technique for Discrimination between Transient and Permanent Faults in Transmission Networks," Electric power component and systems, vol. 45, no. 4, pp. 366-381, 2017.

[5] A. R. Adly, R. A. El Sehiemy, A. Y. Abdelaziz, N. M. A. Ayad, "Critical Aspects on Wavelet Transforms Based Fault Identification Procedures in HV Transmission Line," IET Generation Transmission \& Distribution, vol. 10, no. 2, pp. 508-517, 2016.

[6] A. R. Adly, R. A. El Sehiemy, A. Y. Abdelaziz, "A novel single end measuring system based fast identification scheme for transmission line faults," Measurement, vol. 103, pp. 263-274, 2017.

[7] S. R. Samantaray, "A systematic fuzzy rule based approach for fault classification in transmission lines," Applied Soft Computing, vol. 13, no. 2, pp. 928-938, February 2013.

[8] H. Livani and C. Y. Evrenosoğlu, "A Fault Classification and Localization Method for Three-Terminal Circuits Using Machine Learning," in IEEE Transactions on Power Delivery, vol. 28, no. 4, pp. 2282-2290, Oct. 2013. 
[9] A. Esmaeilian, T. Popovic, M. Kezunovic, "Transmission line relay mis-operation detection based on timesynchronized field data," Electric Power Systems Research, vol. 125, pp. 174-183, August 2015.

[10] M. R. Noori and S. M. Shahrtash, "Combined Fault Detector and Faulted Phase Selector for Transmission Lines Based on Adaptive Cumulative Sum Method," in IEEE Transactions on Power Delivery, vol. 28, no. 3, pp. 17791787, July 2013.

[11] J. Upendar, C.P. Gupta, G.K. Singh, "Statistical decision-tree based fault classification scheme for protection of power transmission lines", Electrical Power and Energy Systems, International Journal of Electrical Power \& Energy Systems, vol. 36, no. 1, pp. 1-12, March 2012.

[12] Y. Usama, X. Lu, H. Imam, C. Sen, N. C. Kar, "Design and implementation of a wavelet analysis based shunt fault detection and identification module for transmission lines application," IET Generation, Transmission \& Distribution, vol. 8, no. 3, pp. 431-441, 2014.

[13] S. Dasa, S. P. Singha, B. K. Panigrahi, "Transmission line fault detection and location using Wide Area Measurements," Electric Power Systems Research, vol. 151, pp. 96-105, 2017.

[14] M. R. D. Zadeh and R. Rubeena, "Communication-Aided High-Speed Adaptive Single-Phase Reclosing," in IEEE Transactions on Power Delivery, vol. 28, no. 1, pp. 499-506, Jan. 2013.

[15] A. R. Adly, R. A. El Sehiemy, A. Y. Abdelaziz, "An Optimal/Adaptive Reclosing Technique for Transient Stability Enhancement under Single Pole Tripping," Electric Power Systems Research, vol. 151, 348-358, 2017.

[16] F. Zhalefar, M. R. Dadash Zadeh and T. S. Sidhu, "A High-Speed Adaptive Single-Phase Reclosing Technique Based on Local Voltage Phasors," in IEEE Transactions on Power Delivery, vol. 32, no. 3, pp. 1203-1211, 2017.

[17] S. Jamali and A. Parham, "New approach to adaptive single pole auto-reclosing of power transmission lines," in IET Generation, Transmission \& Distribution, vol. 4, no. 1, pp. 115-122, January 2010.

[18] F. D. Zahlay, K. S. R. Rao, T. B. Ibrahim, "A new intelligent autoreclosing scheme using artificial neural network and Taguchi's methodology," IEEE Transactions on Industry Applications, vol. 47, no. 1, pp. 306-313, 2010.

[19] T. A. Kawady, N. I. Elkalashy, A. E. Ibrahim, A. I. Taalab, "Arcing fault identification using combined Gabor Transform-neural network for transmission line," Electrical Power and Energy Systems, vo. 61, pp. 248-258, 2014.

[20] S. F. Huang and X.G. Wang, "A Fault Location Scheme Based on Spectrum Characteristic of Fault Generated High Frequency Transient Signals," IEEE Power \& Energy Society General Meeting, 2009, pp. 1-5.

[21] C. M. Portela, N. H. C. Santiago, O. B. Oliveira and C. J. Dupont, "Modeling of arc extinction in air insulation," in IEEE Transactions on Electrical Insulation, vol. 27, no. 3, pp. 457-563, June 1992.

[22] Y. Goda, M. Iwata, K. Ikeda and S. Tanaka, "Arc voltage characteristics of high current fault arcs in long gaps," in IEEE Transactions on Power Delivery, vol. 15, no. 2, pp. 791-795, April 2000. 